\title{
Coronavirus disease 2019; epidemiology and recommendations
}

\author{
Mousa Ghelichi-Ghojogh ${ }^{1^{*}(\mathbb{D})}$, Ehsan Allah Kalteh ${ }^{2}{ }^{\mathbb{D}}$, Mohammad Fararooei $^{3}$ \\ 'Department of Epidemiology, Student Research Committee, School of Public Health, Shiraz University of Medical Sciences, \\ Shiraz, Iran \\ ${ }^{2}$ Health Management and Social Development Research Center, Golestan University of Medical Sciences, Golestan, Iran \\ ${ }^{3}$ HIV/AIDS Research Center, Shiraz University of Medical Sciences, Shiraz, Iran
}

\section{Correspondence to:}

Mousa Ghelichi-Ghojogh, Email; mghelichi2000@yahoo.com

Received: 14 March 2020 Accepted: 21 March 2020 ePublished: 22 March 2020

\section{Citation: Ghelichi-} Ghojogh M, Allah Kalteh E, Fararooei M. Coronavirus disease 2019; epidemiology and recommendations. J Prev Epidemiol. 2020;5(1):e01 DOI:10.34172/jpe.2020.01

\section{Core tip}

The possibility of COVID-19 should be considered primarily in patients with fever and/or respiratory tract symptoms who have had recent close contact with a confirmed or suspected case of COVID-19. Keywords: COVID-19, Coronavirus, Acute respiratory syndrome coronavirus 2, Fever

$\mathrm{I}$ n December 2019, a novel coronavirus, designated severe acute respiratory syndrome coronavirus 2 (SARS-CoV-2) was identified as the cause of a pandemic of acute respiratory distress in Wuhan, China. In February 2020, the World Health Organization (WHO) named the disease COVID-19, which stands for coronavirus disease 2019 (1). Since the first reports of COVID-19, infection has spread to include more than 80000 cases in China and increasing cases worldwide, prompting the WHO to declare a public health emergency in January 2020 and characterize it as a pandemic in March 2020 (2).

The possibility of COVID-19 should be considered primarily in patients with fever and/or respiratory tract symptoms who have had recent close contact with a confirmed or suspected case of COVID-19, who reside in or have recently (within the prior 14 days) traveled to areas where community transmission has been reported (e.g., China, South Korea, Italia and Japan) or who have had potential exposure from specific settings where COVID-19 cases have been reported (3). Clinicians should also be aware of the possibility of COVID-19 when dealing with patients with severe respiratory illness when no other etiology can be identified (4).

Upon suspicion of COVID-19, infection control measures should be implemented and health authorities to be informed. In health care settings in the United States, the Centers for Disease Control and Prevention
(CDC) recommends a single-occupancy room for patients and gowns, gloves, eye protection, and a respirator for health care personnel. In addition to testing for other respiratory pathogens, a nasopharyngeal swab specimen should be screened for COVID-19. Other samples (such as stool and urine) can also be prepared (5).

Management consists of supportive care. Home management may be possible for patients with mild disease who can be properly isolated in the outpatient setting (6$8)$. In order to reduce the risk of transmission in the community, individuals should be advised to wash hands diligently, practice respiratory hygiene (e.g., cover their cough), and avoid crowds and close contact with ill individuals, if possible. Facemasks are not routinely recommended for asymptomatic individuals to prevent exposure in the community. Social distancing is advised, particularly in locations that have community transmission $(9,10)$.

\section{Authors' contribution}

Authors contributed equally to the manuscript.

\section{Conflicts of interest}

The authors report no conflict of interests.

Ethical considerations

Ethical issues including plagiarism, double publication, and redundancy have been completely observed by the authors.

Funding/Support

There was not financial support. 


\section{References}

1. World Health Organization. Director-General's remarks at the media briefing on 2019-nCoV on 11 February 2020. https://www.who.int/dg/speeches/detail/who-director-generals-remarks-at-the-media-briefing-on-2019-ncov-on-11february-2020. Accessed February 12, 2020.

2. World Health Organization. Director-General's opening remarks at the media briefing on COVID-19 - 24 February 2020 https://www.who.int/dg/speeches/detail/who-director-generals-opening-remarks-at-the-media-briefing-on-covid-19---24february-2020. Accessed February 26, 2020.

3. McIntosh K, Hirsch MS, Bloom A. Coronavirus disease 2019 (COVID-19). UpToDate. https://www.uptodate.com/contents/ coronavirus-disease-2019-covid-19. Accessed March 5, 2020.

4. Centers for Disease Control and Prevention. Updated Guidance on Evaluating and Testing Persons for COVID-19. HAN429. https://emergency.cdc.gov/han/2020/han00429. asp?deliveryName=USCDC_511-DM22015. Accessed March 9, 2020.

5. Centers for Disease Control and Prevention. Interim Guidelines for Collecting, Handling, and Testing Clinical Specimens from Persons under Investigation (PUIs) for Coronavirus Disease 2019 (COVID-19). February 14, 2020. https://www.cdc.gov/ coronavirus/2019-nCoV/lab/guidelines-clinical-specimens. html. Accessed March 15, 2020.

6. Centers for Disease Control and Prevention. Interim Clinical Guidance for Management of Patients with Confirmed 2019
Novel Coronavirus (2019-nCoV) Infection, Updated February 12, 2020. https://www.cdc.gov/coronavirus/2019-ncov/ hcp/clinical-guidance-management-patients.html. Accessed February 14, 2020

7. World Health Organization. Novel Coronavirus (2019-nCoV) technical guidance: Patient management. https://www.who. int/emergencies/diseases/novel-coronavirus-2019/technicalguidance/patient-management. Accessed February 2, 2020.

8. World Health Organization. Home care for patients with suspected novel coronavirus ( $\mathrm{nCoV}$ ) infection presenting with mild symptoms and management of contacts. Updated February 4, 2020. https://www.who.int/publications-detail/homecare-for-patients-with-suspected-novel-coronavirus-(ncov)infection-presenting-with-mild-symptoms-and-managementof-contacts. Accessed February 14, 2020.

9. Centers for Disease Control and Prevention. Get your mass gatherings or large community events ready. https://www.cdc. gov/coronavirus/2019-ncov/community/large-events/massgatherings-ready-for-covid-19.html. Accessed March 17, 2020.

10. World Health Organization. Advice on the use of masks the community, during home care and in health care settings in the context of the novel coronavirus (2019-nCoV) outbreak. January 29, 2020. http://www.who.int/publications-detail/ advice-on-the-use-of-masks-the-community-during-homecare-and-in-health-care-settings-in-the-context-of-the-novelcoronavirus-(2019-ncov)-outbreak. Accessed January 31, 2020. 